\section{Subjective Well-being in Broken Home Individual: A Case Study in Ambon}

\author{
Barsyelina Cristy Kona ${ }^{1}$, Yulius Yusak Ranimpi ${ }^{2}$, \\ Simon Pieter Soegijono ${ }^{3}$ \\ ${ }^{1,2}$ Universitas Kristen Satya Wacana, Salatiga \\ ${ }^{3}$ Universitas Kristen Indonesia Maluku \\ email : yulius.ranimpi@staff.uksw.edu
}

Journal PSIKODIMENSIA

Volume 18, No. 1, Januari - Juni 2019

ISSN cetak : 1411-6073

ISSN online : 2579-6321

DOI 10.24167/psidim.v18i1.1771

\begin{abstract}
The problem and purpose of this study is to describe subjective well-being towards broken home individuals. The subjects in this study were only one criteria, who is individual were victims of divorce for more than ten years. The research method used is qualitative research with case study design. The type of qualitative approach used is descriptive phenomenology. Data collection techniques used are structured interviews and observation. Data analysis techniques used data reduction, data display, and conclusion drawing verification. Tools and materials in this study used pens, books, recording devices (tape recorder). Based on the results of the study, it can be concluded that (1) life satisfaction, (2) negative impacts, (3) expectations, (4) need fulfillment, affect subjective-well being towards broken home individuals.
\end{abstract}

Keywords: Family function, subjective well-being, the impact of divorce on children.

\section{PENDAHULUAN}

Crocker dan Canevello dalam Hutagalung (2015) mengatakan bahwa manusia adalah makhluk sosial dan mereka sangat membutuhkan dukungan dari orang lain, baik fisik maupun psikologis. Manusia adalah mahkluk yang tidak dapat hidup sendiri, sehingga manusia dikategorikan sebagai makhluk sosial yang saling ketergantungan satu dengan yang lainnya. Hasil penelitian Hutagalung (2015) juga menyatakan bahwa tidak ada manusia yang dapat bertahan hidup seorang diri saja karena sesungguhnya kodrat manusia itu adalah makhluk sosial, yang dalam interaksinya pasti akan selalu bersinggungan dengan lingkungan sesamanya.

Relasi awal dalam kehidupan manusia sebagai makhluk sosial dimulai dari keluarga, dan keluarga merupakan ruang lingkup sosial yang terkecil (Hutagalung, 2015). Oleh sebab itu manusia membentuk sebuah kesatuan kecil yaitu keluarga. Keluarga dibentuk agar manusia dapat berinteraksi satu dengan yang lain (Habibahi et,al 2012).

Sebuah keluarga inti terdiri dari ayah, ibu dan anak yang mempunyai fungsinya masing-masing, dan jika fungsi tersebut tidak berjalan dengan baik maka akan muncul permasalahan, lambat laun keluarga menjadi tidak harmonis (Heryanto,2016). Terdapat delapan fungsi keluarga dalam kehidupan, yaitu fungsi agama, sosial budaya, cinta kasih sayang, perlindungan, reproduksi, sosialisasi dan pendidikan ekonomi dan lingkungan (Wirdhana et.al 2015). Melalui keluarga anak dikenalkan dengan aturan agama, etika sopan santun, aturan masyarakat, dan aturan-aturan tidak tertulis lainnya yang diharapkan dapat menjadi landasan kepribadian anak dalam menghadapi lingkungan (Rozano et.al 2016). Keluarga juga yang akan selalu memberikan dukungan bagi anak-anak, bila anak tersebut diperhadapkan dengan 
permasalahan-permasalahan dalam kehidupannya.

Fungsi dari sebuah keluarga sangatlah penting bagi tumbuh kembang anak. Jika orang tua melakukan fungsinya dengan baik, maka akan berdampak positif bagi anak, begitu juga sebaliknya. Astuti dan Anganthi (2016), dalam penelitiannya mengatakan, jika keluarga melakukan fungsinya dengan baik maka anak akan memiliki sifat terbuka, merasa bahagia, pergaulan sosial yang baik dan selalu bersemangat menjalani hidup, meskipun ada masalah yang dihadapi, sedangkan keluarga yang tidak melakukan fungsinya dengan baik membuat anak tersebut selalu merasa jengkel, sering marah-marah dan merasa binggung ketika menghadapi semua masalah. Hasil penelitian Mawarsih et.al (2013) menyatakan bahwa fungsi keluarga sangat berperan penting dalam menigkatkan prestasi anak di sekolah.

Dari hasil uraian di atas dapat disimpulkan bahwa fungsi dari sebuah keluarga sangat penting dalam kehidupan seseorang, karena keluarga adalah tempat seseorang bertumbuh, berkembang dan terbentuk karakternya, sehingga jika fungsi keluarga tidak berlangsung dengan baik, maka akan berdampak besar bagi pertumbuhan dan perkembangan anak tersebut. Dampak tersebut bisa dilihat dari kasus-kasus broken home.

Menurut Willis (2008), pengertian broken home bisa dilihat dari dua aspek, yaitu : pertama, struktur keluarga yang tidak utuh karena salah satu kepala keluarga meninggal atau terjadi perceraian. Kedua, struktur keluarga yang tidak utuh karena orang tua tidak peduli dan tidak melakukan fungsi dan perannya sebagai orang tua, karena mereka sibuk dengan kesibukannya sendiri.

Rice dan dolgin dalam Dewi dan Utami (2008) mengatakan beberapa peneliti sebelumnya menyebutkan bahwa perceraiaan akan sangat beresiko besar pada anak, baik secara psikologis, kesehatan maupun akademis. Pada saat orang tua bercerai, sikap, perilaku, dan perasaan pada anak dapat berubah. Menurut McDermot dalam Dewi dan Utami (2008), secara klinis anak akan mengalami depresi seiring dengan perceraian orang tua. Hetherington dalam Dewi dan Utami (2008), juga mengatakan bahwa setelah enam tahun perceraian orang tua, anak akan bertumbuh menjadi seseorang yang tidak merasa bahagia, merasa kesepian, merasa tidak nyaman, dan merasa cemas. Sedangkan akibat ketidak harmonisan sebuah keluarga adalah, anak-anak akan merasa sedih, pendendam, hingga perilaku anak tersebut tidak terkontrol dan menjadi nakal (Kartono, 2010). Sukoco, Rozano, dan Utami (2016) juga mengatakan dalam hasil penelitiannya bahwa perceraian orang tua sangat berpengaruh terhadap perilaku agresif.

Ditambahkan juga oleh Sukoco, Rozano, dan Utami (2016) dalam hasil penelitiannya, bahwa anak yang mempunyai perilaku yang agresif tidak memiliki motivasi untuk belajar sehingga prestasi pada anak di sekolah juga akan menurun. Ketika kedua orang tua bercerai maka anak akan merasa kurangnya perhatian dari kedua orang tua. Begitu juga dalam hal prestasi, perhatian dari kedua orang tua sangat dibutuhkan oleh anak karena salah satu faktor yang berpengaruh dalam hal akademik adalah orang tua. Menurut Slameto (2010) keberhasilan belajar anak di pengaruhi oleh orang tua. Hasil penelitian Mawarsih et.al, (2013) memperkuat bahwa perhatian dari orang tua sangat berpengaruh untuk meningkatkan prestasi anak di sekolah.

Dapat disimpulkan bahwa broken home adalah kondisi keluarga yang tidak harmonis disebabkan oleh perceraian kedua orang tua. Perceraian juga mempunyai dampak bagi anak-anak baik secara psikologis, akademis dan 
kesehatan. Dengan penjelasan di atas nampak bahwa keluarga adalah segalanya, dan dari keluarga sebuah kebahagiaan itu muncul dan berawal. Seligman dalam Astuti dan Anganthi (2016), kebahagiaan biasanya disebut juga dengan istilah subjective well-being (SWB). Kebahagiaan adalah suatu hal yang sangat penting dan semua orang inginkan. Thomas dan Diener dalam Astuti dan Anganthi (2016) menemukan bahwa suasana hati individu akan dipengaruhi oleh kebahagiaan pada saat tertentu. Di sisi lain, kebahagiaan juga berkaitan dengan seberapa mampu individu mempersepsikan pengalaman hidupnya secara positif seperti peristiwa yang meningkatkan kebahagiaan (pernikahan, kelahiran anak, kesuksesan) atau peristiwa menyedihkan yang mampu menurunkan kebahagiaan (kematian kerabat, perceraian dan kegagalan). Dengan demikian tingkat kabahagiaan seseorang akan berubahubah seiring berjalannya waktu (Astuti dan Anganthi, 2016).

Carr dalam Here dan Priyanto (2014), subjective well-being adalah kondisi dimana seseorang mengevaluasi kehidupannya sendiri tentang kepuasaan hidupnya, dan mengevaluasi rendah atau tingginya afeksi positif dan negatif Tingkat SWB dikatakan tinggi apabila orang tersebut merasakan kepuasan dalam hidup, sering merasakan emosi positif seperti gembira dan kasih sayang, serta jarang merasakan emosi negatif seperti kesedihan dan amarah. SWB juga sebagai penentu kualitas hidup seseorang, karena SWB dapat mempengaruhi kehidupan seseorang. Individu dengan tingkat SWB yang tinggi akan merasa percaya diri, dapat menjalani hubungan sosial dengan baik, selain itu juga mereka dapat beradaptasi dengan baik sehingga mereka merasakan kehidupan yang lebih baik.

Dalam kaitan antara SWB dengan fenomena perceraian, Dewi dan Utami (2008) mengatakan bahwa perceraian orang tua adalah salah satu faktor yang mempengaruhi rendahnya SWB pada anak. Anak akan merasa terguncang secara psikologis dan tidak merasa nyaman karena mengalami hal yang tidak mereka inginkan. Sikap merekapun lama kelamaan akan berubah menjadi pemalu, sedih, kecewa, pemarah, dan rasa iri pada teman-teman yang memiliki keluarga yang harmonis.

Astuti dan Angathi (2016), dalam penelitiannya juga mengatakan bahwa rendah dan tingginya SWB pada anak tergantung dari, bagaimana fungsi keluarga bagi anak tersebut. Jika keluarga melakukan fungsinya dengan baik maka SWB pada anak cenderung tinggi, begitu juga sebaliknya SWB pada anak cenderung rendah bila fungsi keluarga tidak di lakukan dengan baik sehingga afek negatif pada anak tersebut muncul. Salah satu contoh yang dapat menurunkan SWB pada anak yaitu perceraian. Perceraian orang tua dapat membuat SWB pada anak menjadi rendah karena dampak dari perceraian tersebut membuat kondisi dan status emosional anak akan terganggu.

Berdasarkan pemahaman yang telah diuraikan di atas peneliti ingin mendeskripsikan SWB pada individu yang kedua orang tuanya mengalami perceraian di Desa Halong Kecamatan Baguala, Kota Ambon. Penelitian memiliki tujuan untuk mendeskripsikan subjective well-being pada individu broken home.

\section{METODE}

Penelitian ini dilaksanakan kurang lebih empat bulan dari bulan Februari 2018- Mei 2018, di Desa Halong Kecamatan Baguala, kota Ambon.

Penelitian ini menggunakan metode penelitian kualitatif. Penelitian kualitatif biasa disebut juga metode penelitian naturalistik, karena penelitiannya dilakukan pada kondisi yang alamiah (natural setting). Metode penelitian ini cenderung menggunakan 
analisa data yang bersifat induktif berdasarkan fakta-fakta yang ditemukan di lapangan dan kemudian dikonstruksikan menjadi hipotesis atau teori (Sugiyono, 2008).

Desain penelitian kualitatif yang dipakai adalah jenis penelitian studi kasus. Studi kasus (case studies) merupakan jenis penelitian yang mendalam dalam waktu tertentu (Sugiarto, 2015). Tipe penelitiannya yang dipakai yaitu tipe pendekatan fenomenologi deskriptif dan fokus penelitiannya adalah untuk mendeskripsikan subjective well-being pada individu dengan latar belakang broken home. Hanya ada satu partisipan dengan kriteria, individu adalah korban perceraian orang tua, selama lebih dari sepuluh tahun. Pengumpulan data juga akan dilakukan terhadap keluarga beserta dengan warga di sekitar tempat tinggal, agar dapat mendukung informasi yang telah diberikan partisipan kepada peneliti.

Metode pengumpulan data yang digunakan dalam penelitian ini adalah : (a) Wawancara terstruktur (Structured interview). Wawancara terstruktur digunakan sebagai teknik pengumpulan data, bila peneliti atau pengumpul data telah mengetahui dengan pasti tentang informasi apa yang akan diperoleh (Sugiyono, 2008). Cara ini digunakan untuk mendapatkan informasi dengan cara bertanya langsung. Esterberg dalam Sugiono (2008) mengatakan bahwa wawancara merupakan pertemuan dua orang untuk bertukar informasi dan ide melalui tanya jawab. Alat dan bahan yang digunakan dalam penelitian ini adalah pulpen, buku, alat perekam (tape recorder) dan panduan wawancara. (b) Observasi Deskriptif. Observasi deskriptif dilakukan peneliti pada saat memasuki situasi sosial tertentu sebagai objek penelitian. Observasi tahap ini sering disebut juga sebagai grand tour observation, dimana observasi ini, peneliti melakukan penjelajah umum, dan menyeluruh, melakukan deskripsi terhadap semua yang dilihat, didengar, dan dirasakan sehingga peneliti menghasilkan kesimpulan pertama (Sugiyono, 2008).

Teknik analisa data yang digunakan dalam penelitian ini mengacu pada teori yang dikemukkan oleh Miles dan Huberman, dalam Sugiyono (2008), dengan beberapa tahap yaitu data reduction (reduksi data), data display (penyajian data), dan conclusion drawing/verification. Data reduction (reduksi data) berarti merangkum data, memilih dan memfokuskan hal-hal yang penting dicari tema dan polanya. Dengan demikian data yang telah direduksi akan memberikan gambaran yang lebih jelas dan mempermudah peneliti untuk melakukan pengumpulan data selanjutnya. Data display (penyajian data) merupakan hasil dari reduksi data yang penyajiannya dalam bentuk teks yang bersifat naratif, agar dapat memudahkan dalam memahami masalah yang terjadi. Tahap yang ke tiga dalam menganalisa data adalah conclusion drawing atau verification (Sugiyono, 2008).

Dalam penelitian ini, peneliti menggunakan triangulasi untuk menguji kredibilitas data. Menurut Wiliam Wiersma dalam Sugiyono (2008), triangulasi dalam pengujian kredibilitas diartikan sebagai pengecekan data dari berbagai sumber dengan berbagai cara, dan berbagai waktu.

\section{HASIL}

$\begin{array}{rcr}\text { Berdasarkan } & \begin{array}{c}\text { hasil } \\ \text { kategori }\end{array} & \text { penelitian, } \\ \text { terdapat } 4 & 4 & \text { untuk }\end{array}$ mendeskripsikan subjective well being pada individu broken home, yaitu kategori kepuasan hidup, kategori dampak negatif, kategori harapan dan kategori pemenuhan kebutuhan. 
1. Kategori Kepuasan Hidup.

Dalam kategori ini terdapat beberapa sub kategori yaitu bahagia dan bersyukur.

a. Sub kategori bahagia.

Saat terjadi perceraian, partisipan masih duduk di bangku kelas 4 SD. Semenjak terjadi perceraian itu, partisipan mengikuti salah satu orang tuanya, yaitu ibu. Namun, sang ibu tidak melakukan peran dan fungsi yang selayaknya. Setelah terjadi perceraian, sang ibu menjalani hubungan dengan laki-laki lain yang lebih muda. Kebiasaan ibu partisipan setelah berpisah dengan ayah partisipan juga, yaitu suka mencari pinjaman uang, tidak pernah pulang ke rumah selama berbulan-bulan dan jikapun pulang tidak mempunyai fungsi bagi partisipan. Tapi, ketika partisipan duduk di bangku SMA, mulai ada perubahan sikap dari ibu partisipan. Ibu partisipan mulai melakukan peran dan fungsinya sebagai orang tua yang mencari nafkah, memberikan perhatian untuk partisipan, sehingga membuat partisipan merasa bahagia karena setelah sekian lama baru partisipan bisa merasakan kasih sayang dari seorang ibu. Berikut pernyataan partisipan :

"Ketika kami sekolah, sosok ibu untuk kami itu tidak ada"

"Ibu itu seperti gila laki-laki, suka pacaran dengan laki-laki yang lebih muda, suka mencari pinjaman uang dimana-mana, dan tidak pulang ke rumah selama berbulanbulan."

"Kami berpisah dari ayah sudah lama, dari kami SD kelas 4. Dari kelas 4 SD kami sudah tidak merasakan adanya ayah dalam kehidupan kami. Kalu ibu memang betul-betul kami rasakan saat saya duduk dibangku SMA"
"Sampai saat ini sosok ibu sudah ada untuk kami, ibu yang berjualan mencari uang unutk nafkahi kami."

b. Sub kategori bersyukur.

Akibat perceraian orang tuanya, partisipan tidak bisa merasakan kasih sayang dan perlindungan dari kedua orang tua. Partisipan juga mendapatkan perlakuan yang kurang baik dari paman dan bibi. Partisipan selalu direndahkan karena tidak ada sosok seorang ayah yang melindungi dan sosok seorang ibu yang dapat mengasihinya. Sekalipun mendapatkan perlakuan yang buruk, tetapi partisipan tidak mempunyai dendam atau niat buruk, atau untuk membalas perlakuan paman dan bibinya, malah partisipan tetap ingin melakukan yang terbaik untuk paman dan bibinya tersebut.

Partisipan mengatakan, meskipun kondisinya seperti itu, tapi diri-nya selalu mengucap syukur, karena masih ada salah satu bibinya yang peduli dan selalu memberikan kasih sayang, yang tidak partisipan dapatkan dari kedua orang tuanya. Partisipan selalu berdoa kepada Tuhan untuk menyerahkan semua masalah yang dihadapinya, karena ia yakin bahwa Tuhan pasti akan memberikan jalan keluar dan Tuhan tidak akan pernah meninggalkannya sendirian. Berikut pernyataan partisipan:

"Kalau tidak ada keluarga kita tidak tau bisa bertahan hidup sampai saat ini atau tidak"

"Tanpa keluarga kita tidak bisa berkembang, bertumbuh, tidak bisa mendapat pendidikan dan tidak dapat makan".

"keluargalah yang melihat kehidupan kita, saat orang tua kita tidak ada"

"Dalam keluarga itukan kami harus saling mengasihi, saling 
membantu. Ketika bibi-bibi saya lagi dalam kesusahan tetap saya akan membantu, meskipun saya juga dalam kesusahan. Tapi, ketika saya susah tidak ada yang bisa membantu saya. Tidak ada rasa mengasihi dalam saling membantu didalam rumah."

"saya harus mensyukuri apa yang saya jalani sekarang dan saya mengucap syukur dengan cara berdoa walaupun masalah seberat apapun tapi ketika saya bersyukur, Tuhan tidak pernah meninggalkan kita, Tuhan selalu ada untuk kami.,"

"dengan kita bersyukur, dengan bersabar, pasti Tuhan buka jalan untuk kami, tidak mungkin tidak. Tuhan tidak mungkin meninggalkan kami kelaparan sampai mati kelaparan, tidak mungkin."

"Apa yang telah dilakukan oleh keluarga saya kepada saya, saya tidak peduli, saya anggap biasa saja. jika keluarga saya salah atau tidak peduli kepada saya, saya tidak simpan didalam hati, saya tidak dendam dan untuk saya pribadi, memaafkan itu penting apalagi untuk keluarga.",

\section{Kategori Dampak Negatif}

Dalam ketegori ini terdapat 2 sub kategori, yaitu emosi negatif dan trauma.

a. Sub kategori emosi negatif

Partisipan merasa kecewa dengan perceraian kedua orang tuanya. Akibat dari perceraian tersebut membuatnya menjadi terlantar karena tidak mendapatkan perhatian, kasih sayang dari orang tua sehingga kehidupannya tidak terkontrol dan menjadi bebas serta mengakibatkan partisipan mendapatkan anak di luar nikah. Partisipan juga kurang dipedulikan oleh paman dan bibi yang se-rumah dengan partisipan. Perlakuan mereka kepada partisipan buruk sehingga membuat partisipan menjadi stres dan kadang melampiaskan amarahnya kepada anak-anaknya. Berikut kutipan partisipan :

"Saya merasa kecewa kepada orang tua saya karena mereka hanya mementingkan diri mereka sendiri hingga akhirnya mereka bercerai dan kami sebagai anak-anak menjadi sasaran"

"karena kedua orang tua, kami merasa terlantar, tidak mendapatkan kami sayang dan perhatian dari orang tua sehingga membuat

kehidupan kami menjadi bebas. Sampai akhirnya saya yang seharusnya belum menikah, saya su harus menikah karena faktor orang tua."

"kami sekarang tinggal bersama dengan paman dan bibi saya, kami merasa tidak bahagia dan saya merasa hidup seperti di neraka karena mereka memperlakukan saya seperti seorang pembantu didalam rumah, dan itu yang kadang membuat saya stres dan saya melampiaskannya kepada anak-anak saya."

\section{b. Sub kategori trauma}

Dampak dari perceraian orang tua juga membuat partisipan trauma dan takut ditinggalkan oleh pasangannya, sekalipun mereka belum mempunyai ikatan pernikahan yang resmi. Partisipan juga takut kehidupannya akan sama seperti ibunya, yang hidup bersama anak-anak tanpa seorang suami. Berikut kutipan partisipan :

"Mungkin, trauma maksudnya saya juga tidak mau. Saya juga berfikir nanti saya sama seperti ibu saya." 
"saya sendiri juga takut karena nanti suatu saat, contohnya kami berduakan belum mempunyai ikatan, tiba-tiba pasangan saya meninggalkan saya dengan anakanak saya dan menikah dengan orang lainkan,saya nanti yang susah."

"Saya takut jangan sampai, saya mengalami hal yang sama seperti ibu saya yang membesarkan kami tanpa seorang suami/ayah."

3. Kategori Harapan

Untuk masa depan, partisipan mempunyai harapan yaitu bisa mendapatkan pekerjaan yang layak agar bisa membantu perekonomian keluarga. Hal ini menjadi penting karena itu adalah salah satu yang bisa ia tunjukan kepada semua orang, bahwa sekalipun kedua orang tuanya telah bercerai, tetapi ia masih bisa membahagiakan ibu dan anak-anaknya dengan cara memberikan kehidupan yang lebih baik.

"Masa depan bagi saya itu sesuatu yang harus saya perjuangkan sampai saya menggapainya"

"saya ingin memperlihatkan kepada semua orang, bahwa kami ini bukan anak-anak broken home, bukan anak-anak terlantar akibat dari ulah ayah dan ibu kami sehingga kami seperti ini. Saya tidak mau memperlihatkan kepada orang lain bahwa memang kami seperti itu, saya ingin menunjukkan kepada orang lain kalau kami bisa menjadi lebih baik dari pada apa yang telah orang lain nilai."

"Mungkin tahun-tahun kedepannya Tuhan membuka jalan agar saya bisa mendapatkan pekerjaan dan bisa merubah kehidupan saya jauh lebih baik dan dapat membahagiakan ibu saya."
4. Kategori pemenuhan kebutuhan (kaitkan dengan penelitian sebelumnya).

Semenjak kedua orang tua partisipan bercerai, perekonomian keluarga partisipan sangat tidak baik. Banyak yang telah partisipan alami selama terjadi perceraian kedua orang tua. Partisipan selalu direndahkan karena tidak mempunyai uang, partisipan merasa susah untuk makan sehari-hari, partisipan tidak membuat tugas-tugas sekolah yang mengeluarkan uang, kadang partisipan dipermalukan guru didepan teman-teman sekolah karena hutang orang tua dan uang sekolah yang belum dilunaskan, sehingga itu yang membuat partisipan kadang merasa putus asa. Akibat dari perceraian kedua orang tua, partisipan menjadi korban dan partisipan juga mengurungkan niatnya untuk melanjutkan pendidikannya ketingkat perkuliahan karena masa-masa yang telah dilalui partisipan membuat partisipan merasa takut untuk semua biaya pendidikan. Berikut kutipan partisipan :

"bibi saya pikir, beliau mempunyai uang sehingga beliau merendahkan kami susah, ibu kami susah dan kami makan saja dengan susah, itu semua karena ayah kami tidak ada, otomatis tidak ada yang menafkahi kami."

"perceraian berpengaruh untuk pendidikan kami karena semua biaya yang kami perlu terkendala, contohnya untuk membayar uang sekolah, ongkos atau jajan ke sekolah dan tugas-tugas yang mengeluarkan uang."

\section{DISKUSI}

Berdasarkan hasil penelitian di atas, didapatkan 4 kategori yaitu kepuasaan hidup, dampak negatif, harapan dan kategori pemenuhan kebutuhan. Berikut adalah pembahasannya : 
Kategori kepuasan hidup

Berdasarkan hasil penelitian dalam kategori kepuasan hidup, terdapat 2 sub kategori didalamnya yaitu sub kategori bahagia dan sub kategori bersyukur. Kedua sub kategori ini muncul karena, saat partisipan duduk di bangku kelas 4 SD hingga bangku SMA, barulah partisipan merasa bahagia, karena sifat dan perilaku ibunya yang telah berubah menjadi lebih baik, serta kasih sayang dan perhatian yang tidak pernah partisipan rasakan selama ini, telah partisipan dapatkan dari ibunya. Dampak dari absennya peran dan fungsi orang tua bagi pertumbuhan dan perkembangan anak yaitu munculnya perilaku-perilaku negatif, seperti yang dikatakan Amalia (2011) dalam jurnalnya, bahwa individu akan melalui masa peralihan dari anak-anak menjadi dewasa dan menuntut anak tersebut untuk menyesuaikan diri, tapi kalau tidak ada orang tua yang mendampinginya, maka akan muncul perilaku-perilaku negatif atau biasanya dikenal dengan istilah kenakalan remaja. Jadi, fungsi dan peran orang tua itu sangat penting bagi pertumbuhan dan perkembangan seseorang. Yuni Rahman Utami (2014) mengatakan bahwa peran orang tua sebagai pendidik, peran sebagai pendorong, peran sebagai panutan, peran sebagai teman, peran sebagai pengawas, dan peran sebagai konselor. Peran orang tua sangat dibutuhkan dalam perkembangan psikologi dan sangat mempengaruhi keberhasilan anak (Utami, 2014).

Selama ibu dan ayah berpisah, partisipan masih bisa merasakan kasih sayang dan dukungan dari salah satu bibi yang selalu menjaga dan merawatnya. Champion dan Goodall dalam Taufik (2010) mengatakan, bahwa dukungan dibutuhkan baik ketika individu sedang menderita maupun dalam kondisi normal, karena adanya dukungan sosial pada kondisi normal dapat menghalau atau dapat menjadi pertahanan kemungkinan terjadi stres pada individu. Dengan demikian, perhatian dan dukungan dari orang terdekat atau bibi partisipan itu sangat penting untuk kehidupan seseorang, karena dengan itu partisipan masih bisa merasakan bahwa dia dipedulikan, dan berharga bagi orang lain. Seperti yang dikatakan juga oleh Wheatley dalam Taufik (2010), bahwa dukungan akan membangun kepercayaan dan kesadaran seseorang bahwa dia dipedulikan, dikasihi, dihargai, bernilai,dan merupakan bagian dari masyarakat yang saling mendukung dan membutuhkan. Dengan dukungan yang masih diterima dari bibinya, partisipan masih tetap mampu bersyukur karena setiap masalah yang dihadapinya, Tuhan selalu memberikan jalan keluar. Astuti dan Anganthi (2016) menambahkan bahwa agama juga mengajarkan seseorang untuk mensyukuri dan menerima segala hal yang tejadi dalam kehidupannya, sehingga partisipan selalu berdoa, mengucap syukur dan selalu menyerahkan masalah partisipan pada Tuhan.

\section{Kategori dampak negatif}

Dampak negatif yang muncul pada anak yang orang tuanya bercerai yaitu respon emosi negatif dan trauma. Emosi negatif muncul karena perceraian orang tuanya, mengakibatkan dirinya terlantar, tidak dipedulikan dan tidak pernah merasakan kasih sayang dan perhatian. Partisipan juga mendapatkan perlakuan yang buruk dari bibi dan pamannya. Hal itu yang membuat partisipan menjadi kecewa dan stres. Reaksi emosional terhadap perceraian, biasa terjadi pada anak semua usia, mencakup kesedihan, ketakutan, depresi, amarah, kebingungan dan kadang kelegaan (Magdalena, 2016). Hasil penelitian Ulpatusalicha (2009), menunjukkan bahwa perilaku sosial anak korban perceraian mengalami ketidakstabilan emosi dikarenakan 
adanya tekanan batin akibat dari masalah yang mereka hadapi dan untuk melampiaskannya, mereka malakukan hal yang berlawanan dengan peraturan seperti memberontak atau hal-hal negatif lainnya.

Dampak dari perceraian juga membuat anak menjadi trauma karena takut ditinggalkan oleh pasangannya, dan nanti kehidupannya akan sama dengan ibunya yang hidup tanpa seorang suami. Seperti yang dikatakan oleh Tanaem (2015) dalam hasil penelitiannya, bahwa kasih sayang yang didapatkan seseorang, mampu menanamkan rasa percaya pada diri, tetapi anak dari korban perceraian tidak mendapatkannya, sehingga membuat anak tersebut sulit untuk menaruh kepercayaannya terhadap orang lain. Dalam hasil penelitian Magdalena (2016) juga mengatakan bahwa ketakutan akan penyebab perceraian kedua orang tua membuat individu takut mengalami hal yang sama seperti yang telah dialami oleh orang tuanya.

Kategori harapan

Kategori harapan ini muncul karena partisipan mempunyai pengalaman yang buruk dengan kehidupannya yang lalu (perceraian orang tua beserta dampaknya), sehingga partisipan menginginkan masa depan yang lebih baik. Safitri (2013), mengatakan bahwa harapan adalah keseluruhan daya kehendak dan strategi yang terbentuk dari pengalaman, serta digunakan oleh individu untuk mencapai sasaran dimasa depan. Farran et.al dalam Safitri (2013) juga menambahkan bahwa harapan terbentuk dari pengalaman hidup yang menekan, bergantung pada spiritualitas dan pada saat yang bersamaan mempertahankan pemikiran rasional untuk menghadapi keadaan. Jadi dari pengalaman atau masalahmasalah yang telah dihadapi partisipan di sekolah maupun di rumah, membuat partisipan tetap bertahan hidup dengan tetap membangun harapan besar untuk bisa mendapatkan pekerjaan yang baik, agar bisa membantu perekonomian keluarga dan bisa membahagiakan orang tuanya.

Kategori pemenuhan kebutuhan

Kategori ini menjelaskan bahwa akibat dari perceraian orang tua membuat partisipan mengurungkan niatnya untuk melanjutkan pendidikan ke tingkat yang lebih tinggi (perguruan tinggi). Hal ini disebabkan masa-masa buruk yang partisipan lalui telah membuatnya khawatir akan biaya pendidikan yang semakin tidak terjangkau. Menurut Leslie dalam Tanaem (2015) bahwa anak korban perceraian sering menderita terkhususnya dalam bagian keuangan. Bumpass dan Rindfuss dalam Tanaem (2015) juga menyatakan, anak-anak yang orang tuanya bercerai, tingkat pendidikan dan ekonomi cenderung rendah serta terjadi ketidakstabilan dalam perkawinannya.

Secara khusus dari kedua kategori yang terakhir ini, peneliti menyimpulkan adanya kondisi dilematis yang dihadapi partisipan. Kondisi itu adalah, adanya kesenjangan antara harapan, yaitu ingin memiliki pekerjaan yang layak/baik, ingin mengubah perekonomian keluarga, tetapi terbentur dengan fakta bahwa dirinya tidak memiliki tingkat pendidikan yang cukup baik untuk mewujudkan harapan itu. Yusuf dalam Muliana et.al, (2016) mengatakan anak korban perceraian yang kurang mendapatkan kasih sayang dan hubungan dengan keluarganya penuh konflik, tegang dan perselisihan, maka remaja tersebut akan mengalami kegagalan dalam mencapai identitasnya secara matang, dan akan mengalami kebingungan, konflik atau frustasi. 


\section{SIMPULAN}

Dari hasil penelitian ini dapat disimpulkan bahwa subjective wellbeing pada individu broken home dipengaruhi oleh kepuasan hidup, dampak negatif, harapan dan pemenuhan kebutuhan. Penelitian ini meneguhkan bahwa, peran dan fungsi orang tua sangat berpengaruh terhadap tumbuh dan kembang anak.

\section{DAFTAR PUSTAKA}

Astuti, Y., dan Anganthi, N. R. N. (2016). Subjective Well-Being Pada Remaja Dari Keluarga Broken Home. Jurnal Penelitian Humaniora, Vol. 17, No. 2,, 161 175.

Amalia, L. (2011). Dampak Ketidakhadiran Ibu Sebagai Tenaga Kerja Wanita (TKW) Terhadap Perkembangan Psikologis Remaja. Kodifikasia, Volume 5 No. 1.

Dewi, P. S., dan Utami, M. S. (2008). Subjective Well-Being Anak Dari Orang Tua Yang Bercerai. Jurnal Psikologi Volume 35, NO. 2, 194 - 212.

Dariani, S. (2016). Relasi Pertetanggaan Pada Remaja Usia Sekolah Menegah Atas (SMA) Di Yogyakarta. Yogyakarta: Perpustakaan Pusat UGM.

Hutagalung, S. (2015). Tiga Dimensi Dasar Relasi Manusia Dalam Kehidupan Sosial. Jurnal Koinonia, Volume 10, Nomor 2.

Habibahi, U., Aisyiyah, N., Ningrum, L. I. (2012). Studi Tentang Status Perkawinan Mahasiswa Reguler Pgsd Tegal Hubungan Dengan Prestasi Akademik. Journalof Elementary Education 1 (1).

Here, S. v., \& Priyanto, P. H. (2014). Subjective Well-Being Pada Remaja Ditinjau Dari Kesadaran
Lingkungan. Psikodimensia Vol. 13.

Heryanto. (2016). Pembinaan Keluarga Broken Home. Jurnal Edueksos Volume V No 1,.

Kartono, K. (2010). Psikologi Wanita Jilid 2 : Mengenal Wanita sebagai ibu dan Nenek. Bandung : Mandar Maju

KW, S., Rozano, D., dan Utami, T. S. (2016). Pengaruh Broken Home Terhadap Perilaku Agresif. Jurnal Penelitian Tindakan Bimbingan dan Konseling.

Magdalena, D. (2016). Komitmen Untuk Menikah Pada Individu Dewasa Yang Orang Tuanya Mengalami Perceraian Disertai Kerkerasan. Salatiga: Psikologi,Universitas Kristen Satya Wacana.

Mawarsih, S. E., Susilaningsih, dan Hamidi, N. (2013). Pengaruh Perhatian orang Tua Dan Motivasi Belajar Terhadap Prestasi Belajar Siswa SMA Negeri Jumapolo. JUPE UNS.

Muliana., Ahmad, A., dan Yuhasriati. (2016). Perkembangan Perilaku Anak Dari Keluarga Yang Bercerai Di Kecamatan Ulim Kabupaten Pidie Jaya. Jurnal Ilmiah Mahasiswa Pendidikan Anak Usia Dini.

Rozano dkk. (2016). Pengaruh Broken Home Terhadap Perilaku Agresif. Jurnal Penelitian Tindakan, Bimbingan dan Konseling Vol. 2 no. 1:38-42. Tegal. Universitas Pancasakti.

Slameto. (2010). Belajar dan faktorfaktor yang mempengaruhinya. Jakarta: Rineka Cipta

Sugiyono. (2008). Metode Penelitian Kuantitaf, Kualitatif dan R \& D. Bandung: Penerbit Alfabeta. 
Sugiarto, E. (2015). Menyusun Proposal Penelitian Kuanlitatif: Skripsi dan Tesis. Yogyakarta: Suaka Media.

Safitri, A. H. (2013). Studi Deskriptif Tingkat Harapan Pada Penderita Penyakit Ginjal Kronik Di RSUD Prof. DR. Margono Soekarjo Purwokerto Repository Universitas Muhammadiyah Purwokerto.

Taufik. (2010). Psikologi untuk Kebidanan dari Teori ke Praktek.Surakarta: Eastview

Tanaem, L. D. (2015). Kajian Trauma Psikososial Anak Karena Perceraian Orang Tua. Universitas Kristen Satya Wacana.

Utami, Y. R. (2014). Peran Orang Tua Terhadap Penanaman Nilai Kejujuran Anak Dalam Lingkungan Masyarakat Di Dusun I dan II Desa Teba Jawa Kabupaten Pesawaran Tahun 2013. Lampung: Digital Repositiry Unila.

Ulpatusalicha. (2009). Dampak perceraian orang tua terhadap perkembangan emosional anak (studi kasus didesa Pengauban Kec. Lekea Indramayu). Skripsi yang tidak diterbitkan. Yogyakarta : Fakultas Fakultas Tarbiyah, Uin Sunan Kalijaga.

Wirdhana dkk (2015). Buku Pegangan Kader Tentang Bimbingan dan Pembinaan Keluarga Remaja. Jakarta : BKK 